\title{
Editor's Note 2018
}

Folklorica is dedicated to the study of folklore, past and present. The discipline of folkloristics is often overlooked in many western $\mathrm{PhD}$ programs focused on Slavic, East European and Eurasian culture. Nevertheless, it is central to an understanding of culture and how people define themselves as members of social groups, be they family, town or nation. The articles in this issue illustrate the persistence of folklore, even in a digital world. They highlight the centrality and productive nature of legendry in Slavic folklore, a genre that has often been underrepresented in scholarship these regions.

The 2018 issue marks the $20^{\text {th }}$ anniversary of our first publication, then titled SEEFA Journal. The past editors and I have been proud to offer a scholarly exchange among researchers abroad and in North America and to document the folklore of these peoples. In the spirit of this momentous anniversary, SEEFA marked the contribution of foundational scholars at our panels at this year's conference of the Association for Slavic, East European and Eurasian Studies. Adrienne Harris organized a panel dedicated to the first president of this organization, James Bailey, whose seminal contributions on Russian epic have had significant impact here and in Russia. We are also honoring Robert Rothstein's body of work on Slavic and Jewish folk song in a second panel in San Francisco. They have been supportive colleagues over years to many a junior scholar and have always been diligent advocates for this journal and for folkloristics. Folklore, as we know, loves a triad. My own mentor, Natalie Kononenko, retired this year after decades in the field studying Slavic and Turkic folklore. She has worked tirelessly for the success of SEEFA since it was founded, serving as its president and journal editor as well. This issue is dedicated to these excellent scholars, friends and colleagues.

Jeanmarie Rouhier-Willoughby, Editor 